\title{
Preparation of a bio-based epoxy with comparable properties to those of petroleum-based counterparts
}

\author{
X. Q. Liu*, W. Huang, Y. H. Jiang, J. Zhu, C. Z. Zhang \\ Polymers and Composites Division, Ningbo Institute of Materials Technology and Engineering, Chinese Academy of \\ Sciences. Ningbo 315201, P.R.China
}

Received 12 August 2011; accepted in revised form 21 October 2011

\begin{abstract}
In this paper a bio-based epoxy with outstanding thermal and mechanical properties was synthesized using a rosin-based epoxy monomer and a rosin-based curing agent. The chemical structures of rosin based epoxy monomer and curing agent were confirmed by Nuclear Magnetic Resonance (NMR) and Fourier Transform Infrared (FT-IR) spectra. The flexural mechanical and dynamic mechanical properties as well as thermal stability of the cured epoxy were investigated. The results showed that the cured epoxy exhibited a glass transition temperature $\left(T_{\mathrm{g}}\right)$ of $164^{\circ} \mathrm{C}$ and its flexural strength and modulus were as high as 70 and $2200 \mathrm{MPa}$, respectively. This indicated that a wholly bio-based epoxy resin possessing high performance was successfully obtained.
\end{abstract}

Keywords: thermosetting resin, bio-based, rosin, thermal properties, mechanical properties

\section{Introduction}

In recent decades, more and more attention has been directed to the bio-based materials because of the diminishing petroleum oil reserves and serious environmental pollution [1]. The conversion of biomass to useful polymers or composites has considerable economical and environmental value. With the rapid development of bio-based materials, more and more natural resources, such as vegetable oil $[2,3]$, starch [4, 5], soy protein [6] and cellulose [7] have been used as the renewable feedstock to produce polymeric materials. Furthermore, these polymers based on renewable resources have often possessed similar properties compared with their petroleum-based counterparts. Up to now, a large quantity of bio-based polymeric materials, such as polylactic acid (PLA) [8], poly(hydroxyalkanoates) (PHA) [9], and castor oil based polyamide [10], have already been commercialized. However, compared with the achieved progress on bio-based thermoplastics, the research on bio-based thermosetting resins, especially the thermosetting resins with high glass transition temperature (higher than $100^{\circ} \mathrm{C}$ ) and comparable mechanical properties with petroleum-based counterparts are very limited.

To the best of our knowledge, plant oil might be the most popular renewable resource in the synthesis of bio-based thermosetting resins [3, 11-13]. But unfortunately, due to the long soft aliphatic chain in triglyceride and its low crosslink density, the resulting resin always has a low glass transition temperature (lower than $100^{\circ} \mathrm{C}$ ) and disappointing mechanical properties. For example, Park et al. [3] synthesized epoxy from soybean oil and caster oil. The results showed that the glass transition temperature of the cured epoxy was lower than $50^{\circ} \mathrm{C}$. Javni et al. [11] and Can et al. [12] also prepared unsaturated polyester or polyurethane from soybean oil derivatives. But their results indicated that the properties of the oil-based resin strongly depended on the

\footnotetext{
${ }^{*}$ Corresponding author, e-mail: liuxq@nimte.ac.cn
}

(c) BME-PT 
incorporation of rigid petroleum chemicals [11-15]. In order to obtain the acceptable mechanical and thermal properties for practical application, the content of the rigid co-monomer was usually as high as $50 \%$ or beyond. Obviously, they were only partly bio-based materials and the petroleum based component played a critical role in determining the properties of these materials. As we know, the thermosetting resin with satisfactory performance $\left(T_{\mathrm{g}}\right.$ is higher than $100^{\circ} \mathrm{C}$ and modulus is higher than $2000 \mathrm{MPa}$ ) derived from bio-based feedstock has seldom been reported [16-18].

Rosin is an important natural product. It is composed of ca. $90 \%$ acidic and ca. $10 \%$ neutral compounds. The hydrogenated phenanthrene ring structure in rosin acids is similar in rigidity to rigid petroleum chemicals. Therefore, we could make use of this bio-based feedstock to synthesize high performance polymeric materials. In our previous works, several kinds of rosin based anhydride type [19] or diimide-diacid type epoxy curing agents [20] were synthesized and their potential in improving the properties of thermosetting resins was demonstrated. In this paper, a rosin based epoxy with three functional groups was synthesized and it was cured with a rosin based curing agent. The objective of this research is to make the full use of rosin rigidity to synthesize a wholly rosin-based thermosetting resin with satisfactory properties, so as to inspire us to explore more and more renewable alternatives to petroleum based polymeric materials.

\section{Experimental section}

\subsection{Materials}

Rosin acid $\left(\mathrm{C}_{20} \mathrm{H}_{30} \mathrm{O}_{2}\right.$, purity of $75 \%$, yellow crystals or chunks, soluble in acetone, petroleum ether, $\mathrm{Et}_{2} \mathrm{O}$ and $\mathrm{EtOH}$, melting point of $139-156^{\circ} \mathrm{C}$ ) was obtained from Aladdin Reagent Co., Ltd. Shanghai. It is actually a mixture of abietic acid and other rosin neutral compounds. Sodium hydroxide, acetic acid, epichlorohydrin, maleic anhydride, $p$-toluenesulfonic acid, 2-ethyl-4-methylimidazole, tetrabutyl ammonium bromide and the common solvents were obtained from Sinopharm Chemical Reagent Co., Ltd., Shanghai, China. All the chemicals were used as received.

\subsection{Characterization}

NMR spectra was recorded on the Bruker (Germany) $400 \mathrm{MHz}$ spectrometer. The samples were dissolved in deuterated chloroform $\left(\mathrm{CDCl}_{3}\right) .{ }^{1} \mathrm{H}-\mathrm{NMR}$ and ${ }^{13} \mathrm{C}$-NMR were obtained at room temperature using Tetramethylsilane (TMS) as the internal standard. Fourier transform infrared (FT-IR) spectra were collected on a Nicolet 6700 FTIR spectrometer. The collecting wavelength was from 4000 to $400 \mathrm{~cm}^{-1}$. Samples were prepared by dissolving a small amount of compound in $\mathrm{CH}_{2} \mathrm{Cl}_{2}$, followed by smearing the solution onto a $\mathrm{KBr}$ crystal plate and evaporating the solvent at room temperature completely. Dynamic mechanical properties were measured by SDTA861e DMA using three-point bending method. Samples were heated from 40 to $250^{\circ} \mathrm{C}$ with a heating rate of $2^{\circ} \mathrm{C} / \mathrm{min}$. and frequency of $1 \mathrm{~Hz}$. Thermogravimetric analysis was performed on Perkin-Elmer Diamond TG/DTA with high purity nitrogen as a purge gas at a scan rate of $10^{\circ} \mathrm{C} / \mathrm{min}$. Elemental analyses were performed by PerkinElmer PE2400 elemental analyzer. Flexural properties were determined by Instron model 5567 (Made in UK) with a $30 \mathrm{kN}$ load cell at the crosshead speed of $2 \mathrm{~mm} / \mathrm{min}$. Unnotched izod impact testing was conducted on XJ-50Z impact testing machine and (Made in Chengde, China). For the mechanical testing, at least five specimens were tested for each sample to obtain the average value for properties.

\subsection{Synthesis of maleopimaric acid (MPA)}

The synthesis, collection and purification of MPA were done according to the procedure described in our former paper $[19,20] .{ }^{1} \mathrm{H}-\mathrm{NMR}\left(\mathrm{CD}_{3} \mathrm{Cl}, \delta\right.$ ppm) $5.5(1 \mathrm{H}), 3.1(2 \mathrm{H}), 2.7(1 \mathrm{H}), 2.5(1 \mathrm{H}), 2.2$ $(1 \mathrm{H}), 1.78-1.24(13 \mathrm{H}), 1.2(3 \mathrm{H}), 1.0(6 \mathrm{H}), 0.6(3 \mathrm{H})$. ${ }^{13} \mathrm{C}-\mathrm{NMR}\left(\mathrm{CD}_{3} \mathrm{Cl}, \delta \mathrm{ppm}\right) 185,173,171,148,125$, $54,53,52,49,47,45,40,38,37,36,35,33,27,22$, 20, 20, 17, 15.76 FT-IR $\left(\mathrm{cm}^{-1}\right) 850,930,944,1010$, 1090, 1140, 1280, 1235, 1390, 1465, 1730, 1782, 1842, 2860, 2942, 3500-3100. Elemental analysis: Calculated \%: C: 71.97, H: 8.05; Found \%: C: 71.42, H: 8.11 .

\subsection{Synthesis of triglycidyl ester of maleopimaric acid}

Into a three-necked round flask equipped with magnetic stirrer, thermometer and reflux condenser, 
$30 \mathrm{~mL}$ of distilled water and $20 \mathrm{~g}(0.05 \mathrm{~mol})$ of maleopimaric acid were charged. After it was heated to $130^{\circ} \mathrm{C}, 6 \mathrm{~g}(0.15 \mathrm{~mol})$ of sodium hydroxide was added gradually and the reaction was maintained at this temperature for $4 \mathrm{~h}$ under nitrogen atmosphere. To this mixture, $46.5 \mathrm{~g}(0.5 \mathrm{~mol})$ of epichlorohydrin and $0.5 \mathrm{~g}$ of tetrabutyl ammonium bromide were added before the reaction was refluxed for another $6 \mathrm{~h}$. It was cooled to $70^{\circ} \mathrm{C}$ after the addition of excess sodium hydroxide. By cooling the reaction to room temperature, the solid precipitation was removed via filtration. The filtrate was diluted by $200 \mathrm{~mL}$ of hexane and washed with distilled water twice. The upper hexane layer was concentrated by rotary evaporator and dried at $60^{\circ} \mathrm{C}$ in the vacuum oven for $12 \mathrm{~h}$ to get the triglycidyl ester of maleopimaric acid weighting $22 \mathrm{~g}$ (Yield: 75\%). ${ }^{1} \mathrm{H}-\mathrm{NMR}$ $\left(\mathrm{CDCl}_{3}, \delta \mathrm{ppm}\right) 5.4(1 \mathrm{H}), 4.3-4.5(3 \mathrm{H}), 3.9-4.0$ (2H), 3.70-3.72 (1H), 3.11-3.32 (3H), 2.78-2.87 (6H), 2.55-2.70 (4H), 2.40-2.42 (1H), 2.18-2.3 (1H), 1.78-1.24 (13H), $1.15(3 \mathrm{H}), 1.00-0.98(6 \mathrm{H})$, $0.59(3 \mathrm{H}) ;{ }^{13} \mathrm{C}-\mathrm{NMR}\left(\mathrm{CDCl}_{3}, \delta \mathrm{ppm}\right) 178.2,173.5$, 172.6, 148.1, 127.4, 65.1, 56.4, 53.5, 52.4, 49.5, 47.2, 45.9, 40.6, 38.2, 37.9, 36.6, 35.6, 35.0, 32.7, 27.1, 21.9, 20.8, 20.2, 17.2, 16.9, 15.8. FT-IR $\left(\mathrm{cm}^{-1}\right)$ 466, 620, 721, 759, 849, 908, 1020, 1071, 1103, 1173, 1249, 1384, 1453, 1730, 2869, 2954, 3446. Elemental analysis: Calculated \%: C: 67.55, H: 7.90; Found \%: C: 67.23, H: 7.82.

\subsection{Cured resin preparation}

Maleopimaric acid and triglycidyl ester of maleopimaric acid in a 1:1 stoichiometeric ratio together with catalyst 2 -ethyl-4-methylimidazole ( $1 \mathrm{wt} \%$ on the basis of total weight) were dissolved in acetone to get the uniform mixture. The solvent was removed in the vacuum oven at $60^{\circ} \mathrm{C}$ for $30 \mathrm{~min}$. The solvent free mixture was transferred to the steel mold with the inner dimension of $64 \mathrm{~mm} \times 10 \mathrm{~mm} \times 5 \mathrm{~mm}$ to prepare the specimens for mechanical and DMA test. The curing reaction was carried out at $120^{\circ} \mathrm{C}$ for $2 \mathrm{~h}, 150^{\circ} \mathrm{C}$ for $2 \mathrm{~h}$ and $180^{\circ} \mathrm{C}$ for $2 \mathrm{~h}$ at normal pressure. The cured samples were left still at room temperature for $12 \mathrm{~h}$ prior to mechanical and DMA testing.

\section{Results and discussion}

The reaction scheme and chemical structure for the triglycidyl ester of maleopimaric acid were shown in Figure 1. The synthesis of maleopimaric acid from rosin acid was described carefully in our former paper [19] and its triglycidyl ester was prepared by the reaction with epichlorohydrin and aqueous sodium hydroxide with tetrabutyl ammonium bromide as the phase transfer catalyst. It is easy to notice that maleopimaric acid was the intermediate product to prepare the rosin-based epoxy monomer. In our previous work, [19] maleopimaric acid was demonstrated to have great potential to replace some of conventional petroleum-based curing agents in synthesis of high performance epoxy resin. Naturally, it was also employed as a curing agent to cure its resulting triglycidyl ester and so as to prepare the wholly rosin-based epoxy resin in this research.

Figures $2 \mathrm{a}$ and $2 \mathrm{~b}$ show the ${ }^{1} \mathrm{H}-\mathrm{NMR}$ and ${ }^{13} \mathrm{C}-\mathrm{NMR}$ spectra for tirglycidyl ester of maleopimaric acid, respectively. In Figure 2a, the peak at 5.4 ppm was assigned to the proton 1 on the unsaturated carbon. The multiple peaks appearing at 4.3-4.5, 3.9-4.0
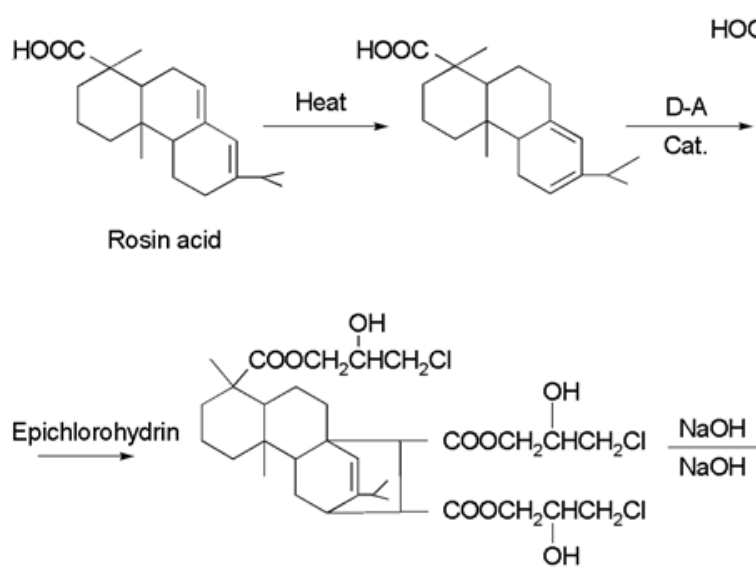

$\mathrm{OH}$

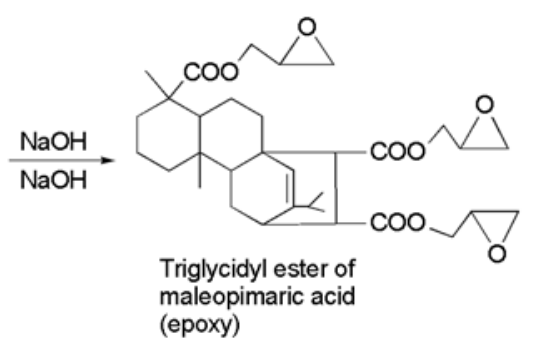

Figure 1. Synthetic route for maleopimaric aicd and its triglycidyl ester 
a)
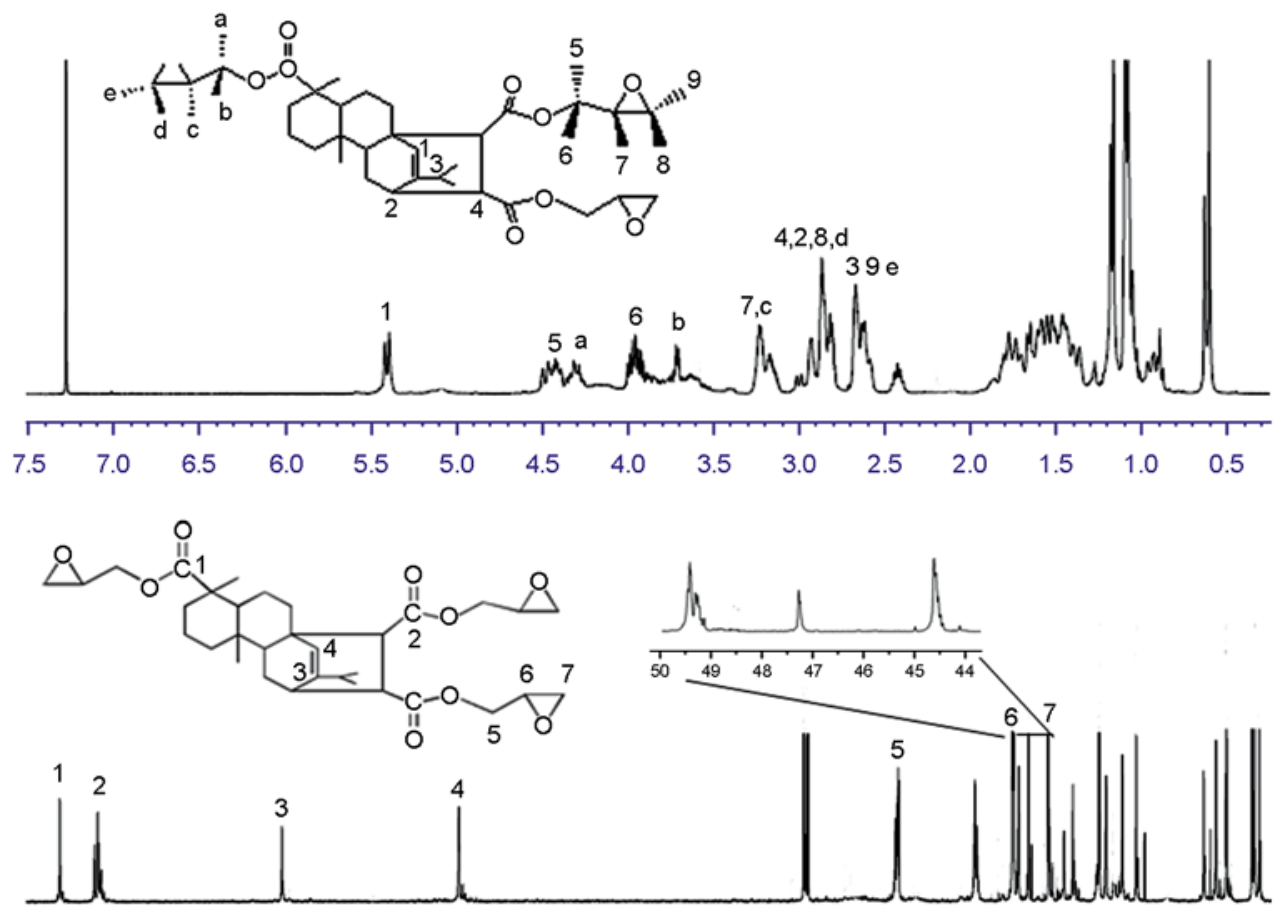

b)

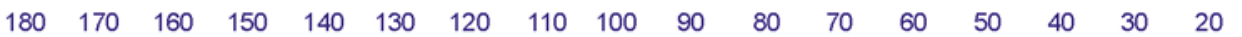

Figure 2. ${ }^{1} \mathrm{H}-\mathrm{NMR}$ and ${ }^{13} \mathrm{C}-\mathrm{NMR}$ spectra for tirglycidyl ester of maleopimaric acid

and 3.70-3.72 ppm were attributed to the proton 5, $\mathrm{a}, 6, \mathrm{~b}$ due to the presence of chital carbon in the ethylene oxide ring. Other specific peaks at 3.1-3.3, 2.78-2.87 and 2.5-2.70 ppm were also identified accordingly. In Figure $2 b$, all the characteristic chemical shift assignments for different carbons in tirglycidyl ester of maleopimaric acid were made. Especially, from the expansion between 45 and $50 \mathrm{ppm}$, the peaks for carbon 6 and carbon 7 on the ethylene oxide ring were clearly observed.

FT-IR is useful to monitor the epoxy curing reaction. Figure 3 is the FT-IR spectra for the mixture of maleopimaric acid and tirglycidyl ester of maleopimaric acid before and after curing reaction. In the unreacted mixture, the bands at 1782 and $1842 \mathrm{~cm}^{-1}$ were assigned to the characteristic peak of anhydride group; the bond at $1730 \mathrm{~cm}^{-1}$ was attributed to the carbonyl stretch $(\mathrm{C}=\mathrm{O})$; the peak at $908 \mathrm{~cm}^{-1}$ indicated the presence of oxirane rings. After curing reaction, the bands at 1782, 1842 and $908 \mathrm{~cm}^{-1}$ were disappeared completely, which represented the conversion of anhydride and epoxy group as well as the formation of the cured resin.

Dynamic mechanical analysis is a popular method to determine the dynamic elastic modulus of polymeric materials and observe the emergence of their

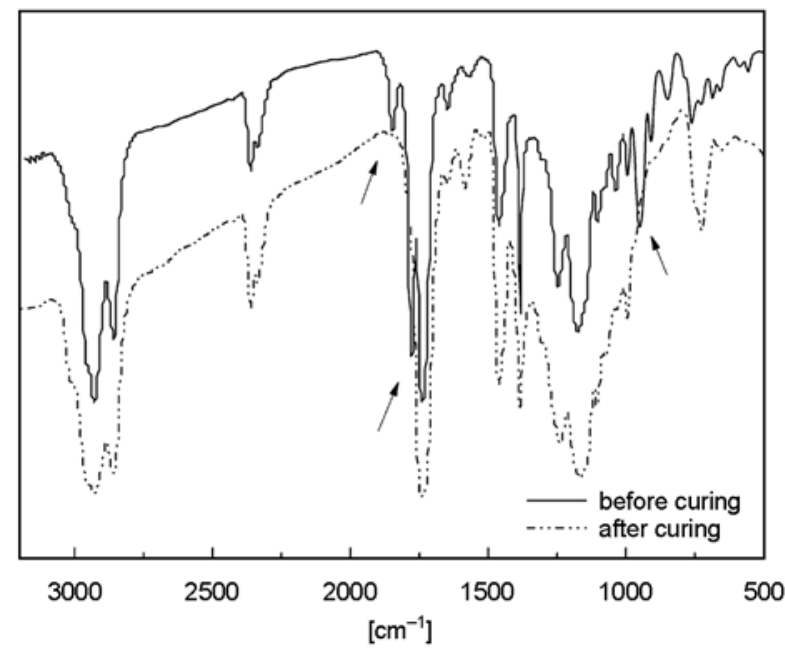

Figure 3. FT-IR spectra for the mixture of maleopimaric acid and tirglycidyl ester of maleopimaric acid before and after curing reaction

molecular mobility transition such as glass transition. Figure 4 shows the dynamic mechanical properties of tirglycidyl ester of maleopimaric acid cured with maleopimaric acid. Apparently, its glass transition temperature $\left(T_{\mathrm{g}}\right)$ and storage modulus at room temperature was as high as $164^{\circ} \mathrm{C}$ and $3.2 \mathrm{GPa}$, respectively. As we know, the plant oil based thermosetting epoxy, unsaturated polyester or polyurethane were widely studied [11-13, 21-23], but their 
Table 1. Mechanical properties and thermal stability of cured tirglycidyl ester of maleopimaric acid and petroleum-based counterparts DEGBA

\begin{tabular}{|l|c|c|c|c|c|}
\hline \multicolumn{1}{|c|}{ Sample } & $\begin{array}{c}\text { Flexural modulus } \\
{[\mathbf{M P a}]}\end{array}$ & $\begin{array}{c}\text { Flexural strength } \\
{[\mathbf{M P a}]}\end{array}$ & $\begin{array}{c}\text { Impact strength } \\
{\left[\mathbf{k J} / \mathbf{m}^{\mathbf{2}}\right]}\end{array}$ & $\begin{array}{c}\text { Strain at break } \\
{[\mathbf{\%}]}\end{array}$ & $\begin{array}{c}\text { Thermal stability }^{\mathbf{a}} \\
{\left[{ }^{\circ} \mathbf{C}\right]}\end{array}$ \\
\hline rosin-based epoxy & $2200 \pm 30$ & $70 \pm 1$ & $2.1 \pm 0.2$ & $1.9 \pm 0.3$ & $T_{5 \%}=328$ \\
\hline DGEBA & $3000 \pm 200[24]$ & $80 \pm 3[24]$ & $3.2[25]$ & $2.6[24]$ & $T_{2 \%}=319[26]$ \\
\hline
\end{tabular}

${ }^{a}$ temperature of $5 \%$ or $2 \%$ thermal degradation

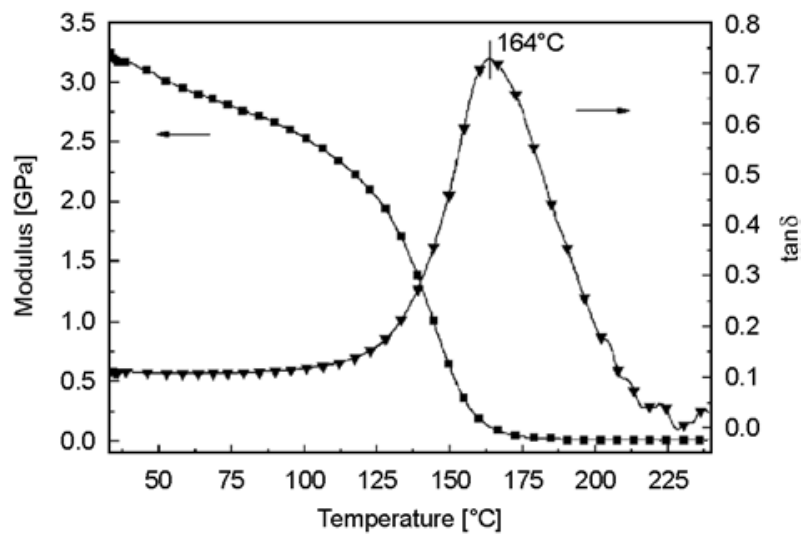

Figure 4. DMA curves for cured tirglycidyl ester of maleopimaric acid

glass transition temperatures and modulus were very low (lower than $50^{\circ} \mathrm{C}$ ). In order to increase their $T_{\mathrm{g}}$ or modulus, more than $50 \%$ petroleumbased rigid monomers must be introduced. To the best of our knowledge, this is the first wholly biobased thermosetting resin which demonstrated outstanding dynamic mechanical properties and thermal properties

To evaluate the properties of this bio-based epoxy resin, the mechanical properties and thermal stability were also investigated. The flexural properties and impact strength were summarized in Table 1. The flexural modulus and flexural strength were about 2200 and $70 \mathrm{MPa}$, respectively, which are comparable with those of petroleum-based bisphenol A epoxy cured with different curing agents [24]. It meant that this wholly bio-based epoxy resin could be use as an engineering thermosetting resin. Although the resin shows a little bit brittleness according to the lower values of the impact strength and strain at break compared with the reported results [24, 25], it is still acceptable. The low impact strength might be due to the high crosslink density of the cured epoxy, since the epoxy monomer and curing agent both have three crosslinkable functionalities.
The thermal stability is also one of the important properties for polymeric materials and TGA is the most convenient method to determine the thermal stability and degradation behaviors of polymers. In Table 1, the TGA result for the cured triglycidyl ester of maleopimaric aicd indicated that its 5\% weight loss occurred at $328^{\circ} \mathrm{C}$, which is also competitive with the petroleum-based bisphenol A epoxy [26]. As we know, the common cured bisphenol A epoxy usually show their 5\% weight loss temperature at about $350^{\circ} \mathrm{C}$.

\section{Conclusions}

A novel bio-based thermosetting resin was developed using a rosin based epoxy monomer and rosin based curing agent. It demonstrated high $T_{\mathrm{g}}$ and modulus. Also its flexural properties and thermal stability were comparable to those of the conventional petroleum-based epoxy. Our results indicated the possibility to synthesize wholly bio-based thermosetting resin with high performance and inspired us to explore more and more renewable alternatives to petroleum based polymeric materials.

\section{Acknowledgements}

Financial supports provided by the Ningbo Natural Science Foundation (Grant No. 2010A610192, 2011A610127), National Natural Science Foundation of China (Grant No. NSFC51003116) and Director's Science Foundation of NIMTE were greatly acknowledged.

\section{References}

[1] Graedel T. E., Howard-Grenville J. A.: Greening the industrial facility, perspectives, approaches and tools. Springer, New York (2005).

[2] Jue L., Knot S., Wool R. P.: New sheet molding compound resins from soybean oil. I. Synthesis and characterization. Polymer, 46, 71-80 (2005). DOI: $10.1016 /$ j.polymer.2004.10.060 
[3] Park S-J., Jin F-L., Lee J-R.: Synthesis and thermal properties of epoxidized vegetable oil. Macromolecular Rapid Communications, 25, 724-727 (2004).

DOI: $10.1002 /$ marc. 200300191

[4] Guan J., Hanna M. A.: Extruding foams from corn starch acetate and native corn starch. Biomacromolecules, 5, 2329-2339 (2004).

DOI: $10.1021 / \mathrm{bm} 049512 \mathrm{~m}$

[5] Qi Q., Wu Y., Tian M., Liang G., Zhang L., Ma J.: Modification of starch for high performance elastomer. Polymer, 47, 3896-3903 (2006).

DOI: $10.1016 /$ j.polymer.2006.03.095

[6] Zhang J., Mungara P., Jane J.: Mechanical and thermal properties of extruded soy protein sheets. Polymer, 42, 2569-2578 (2001).

DOI: 10.1016/S0032-3861(00)00624-8

[7] Kurimoto Y., Takeda M., Koizumi A., Yamauchi S., Doi S., Tamura Y.: Mechanical properties of polyurethane films prepared from liquefied wood with polymeric MDI. Bioresource Technology, 74, 151157 (2000).

DOI: 10.1016/S0960-8524(00)00009-2

[8] Garlotta D.: A literature review of poly(lactic acid). Journal of Polymers and the Environment, 9, 63-84 (2001).

DOI: 10.1023/A:1020200822435

[9] Hazer B., Steinbüchel A.: Increased diversification of polyhydroxyalkanoates by modification reactions for industrial and medical applications. Applied Microbiology and Biotechnology, 74, 1-12 (2007).

DOI: 10.1007/s00253-006-0732-8

[10] Corcuera M. A., Rueda L., d'Arlas F. B., Aebelaiz A., Marieta C., Mondragon I., Eceiza A.: Microstructure and properties of polyurethanes derived from castor oil. Polymer Degradation and Stability, 95, 2175-2184 (2010).

DOI: $10.1016 /$ j.polymdegradstab.2010.03.001

[11] Javni I., Zhang W., Petrovič Z. S.: Effect of different isocyanates on the properties of soy-based polyurethanes. Journal of Applied Polymer Sciences, 88, 2912-2916 (2003).

DOI: 10.1002/app.11966

[12] Can E., Wool R. P., Küsefoğlu S.: Soybean and castor oil based monomers: Synthesis and copolymerization with styrene. Journal of Applied Polymer Sciences, 102, 2433-2447 (2006).

DOI: $10.1002 / a p p .24548$

[13] Çakmaklı B., Hazer B., Tekin İ. Ö., Cömert F. B.: Synthesis and characterization of polymeric soybean oil- $g$ methyl methacrylate (and $n$-butyl methacrylate) graft copolymers: Biocompatibility and bacterial adhesion. Biomacromolecules, 6, 1750-1758 (2005). DOI: $10.1021 / \mathrm{bm} 050063 \mathrm{f}$

[14] Alli A., Hazer B.: Poly( $N$-isopropylacrylamide) thermoresponsive cross-linked conjugates containing polymeric soybean oil and/or polypropylene glycol. European Polmyer Journal, 44, 1701-1713 (2008).

DOI: $10.1016 /$ j.eurpolymj.2008.04.004
[15] Alli A., Hazer B.: Synthesis and characterization of $\operatorname{poly}(N$-isopropyl acryl amide)-g-poly(linoleic acid)/ poly(linolenic acid) graft copolymers. Journal of American Oil Chemistry Society, 88, 255-263 (2011). DOI: $10.1007 / \mathrm{s} 11746-010-1663-1$

[16] Raquez J-M., Deléglise M., Lacrampe M-F., Krawczak P.: Thermosetting (bio)materials derived from renewable resources: A critical review. Progress in Polymer Science, 35, 487-509 (2010). DOI: $10.1016 / \mathrm{j}$. progpolymsci.2010.01.001

[17] Srikanth P.: Handbook of bioplastics and biocomposites engineering applications. Wiley, Salem (2011).

[18] Grishchuk S., Karger-Kocsis J.: Hybrid thermosets from vinyl ester resin and acrylated epoxidized soybean oil (AESO). Express Polymer Letters, 5, 2-11 (2011).

DOI: $10.3144 /$ expresspolymlett.2011.2

[19] Liu X., Xin W., Zhang J.: Rosin-based acid anhydrides as alternatives to petrochemical curing agents. Green Chemistry, 11, 1018-1025 (2009).

DOI: $10.1039 / \mathrm{B} 903955 \mathrm{D}$

[20] Liu X., Xin W., Zhang J.: Rosin-derived imide-diacids as epoxy curing agents for enhanced performance. Bioresource Technnology, 101, 2520-2524 (2010). DOI: $10.1016 /$ j.biortech.2009.11.028

[21] Galià M., de Espinosa L. M., Ronda J. C., Lligadas G., Cádiz V.: Vegetable oil-based thermosetting polymers. European Journal of Lipid Science and Technology, 111, 87-96 (2009). DOI: $10.1002 /$ ejlt.200900096

[22] Şen S., Çaylı G.: Synthesis of bio-based polymeric nanocomposites from acrylated epoxidized soybean oil and montmorillonite clay in the presence of a biobased intercalant. Polymer International, 59, 11221129 (2010). DOI: $10.1002 /$ pi.2838

[23] Keleş E., Hazer B.: Synthesis of segmented polyurethane based on polymeric soybean oil polyol and poly (ethylene glycol). Journal of Polymers and the Environment, 17, 153-158 (2009). DOI: $10.1007 / \mathrm{s} 10924-009-0132-0$

[24] Liu F., Wang Z., Wang Y., Zhang B.: Copolymer networks from carboxyl-containing polyaryletherketone and diglycidyl ether of bisphenol-A: Preparation and properties. Journal of Polymer Science Part B: Polymer Physics, 48, 2424-2431 (2010). DOI: $10.1002 /$ polb.22141

[25] Morell M., Ramis X., Ferrando F., Yu Y., Serra A.: New improved thermosets obtained from DGEBA and a hyperbranched poly(ester-amide). Polymer, 50, 53745383 (2009). DOI: 10.1016/j.polymer.2009.09.024

[26] Jin F-L., Park S-J.: Thermomechanical behavior of epoxy resins modified with epoxidized vegetable oils. Polymer International, 57, 577-583 (2008).

DOI: 10.1002/pi.2280 